\title{
High Pressure Equation of State for Nanomaterials
}

\author{
Jeewan C. Bhatt, ${ }^{1}$ Kuldeep Kholiya, ${ }^{2}$ and Ravindra Kumar ${ }^{3}$ \\ ${ }^{1}$ Department of Physics, National Institute of Technology Uttarakhand, Srinagar 246174, India \\ ${ }^{2}$ Department of Applied Science, B.T. Kumaon Institute of Technology, Dwarahat 263653, India \\ ${ }^{3}$ Department of Physics \& Material Science \& Engineering, Jaypee Institute of Information Technology University, Noida 201307, India
}

Correspondence should be addressed to Jeewan C. Bhatt; jeewan25may@rediffmail.com

Received 22 April 2013; Accepted 5 June 2013

Academic Editors: H. Duan, G. F. Goya, and H. Tang

Copyright (C) 2013 Jeewan C. Bhatt et al. This is an open access article distributed under the Creative Commons Attribution License, which permits unrestricted use, distribution, and reproduction in any medium, provided the original work is properly cited.

\begin{abstract}
Shanker Equation of State is used to study the volume compression of nanocrystalline materials under different pressure. On comparing with the experimental data it gives good results at low pressure, but for higher compression it deviates from the experimental points. Therefore, the Equation of State is modified empirically to study the pressure-volume relation for nanomaterials, namely, $\mathrm{n}-\mathrm{Rb}_{3} \mathrm{C}_{60}, \mathrm{n}$-CdSe (rocksalt phase), $\mathrm{n}-\mathrm{TiO}_{2}$ (anatase and rutile phase), $\mathrm{Fe}$-filled nanotube, and $\gamma-\mathrm{Fe}_{2} \mathrm{O}_{3}$, at high pressure. The results obtained from the empirical Equation of State are found to be in better agreement with the available experimental data.
\end{abstract}

\section{Introduction}

Nanocrystalline materials with particle size of $1-100 \mathrm{~nm}$ are of current interest in discovering novel and chemical properties of materials that may differ from those of the corresponding bulk materials. Nanocrystalline crystallites are generally viewed to consist of two structurally distinct components, a crystalline component formed by a small single crystal with random crystallographic orientation and a surface layer characterized by a significant fraction of atoms at grain boundaries. The nanomaterials are very sensitive to external parameters like pressure and temperature. The study of nanomaterials under high pressure and high temperature is considered as a possible path to expand the range of available solid state materials. Pressure application, as for the bulk materials, allows the continuous modification of the interatomic interaction of the nanoobject and constitutes an invaluable tool to explore physical chemical interactions at the nanoscale and their link with physical properties of interest. The physical properties of materials depend strongly on the structure and interatomic distances. High pressure can vary these distances, which implies that we can study relations between structure and properties of the materials.

High compression occurs due to high pressure. Due to the pressure many effects happen, such as pressure ionization, modification in electronic properties, phase change, and several phenomenons in applied fields.

The knowledge of thermoelastic properties of minerals at high temperature and pressure is required for the understanding of the earth's deep interior. The study based on the Equation of State at high pressure and high temperature is of fundamental interest because it permits interpolation and extrapolation in to the regions in which the experimental data are not available adequately. They help in planning future high-pressure experiments and are also important in comparing static high-pressure experiments with shock wave experiments, in which the treatment of thermal effect is particularly important. Numerous investigations have been reported on the physical and electronic properties of materials with the change in particle size [1-3].

$\mathrm{TiO}_{2}$ is a wide band gap $(3.2 \mathrm{eV})$ semiconductor material. Among the major technological applications of this material are those in the pigments, plastics, cosmetics, electronics, and catalysts industries. It can be used in oil and air purification. It is useful in nitrogen fixation as well as dissociation of water molecule to produce hydrogen gas. It is a promising nonlinear optical material due to its transparency and large refractive index [4]. $\mathrm{TiO}_{2}$ has also served minerals physicists as a model system in the study of pressure-induced structural phase transitions of oxides relevant to the Earth's mantle, 
in particular that of $\mathrm{SiO}_{2}$. It is also known for polymorphism, several natural polymorphs of $\mathrm{TiO}_{2}$ exit [5], and the most common are anatase, rutile, and brookite. Rutile is the stable phase whereas anatase and brookite are metastable. Swamy et al. [6] have presented a synchrotron XRD study of pressureinduced changes in nanocrystalline anatase (with a crystallite size of $30-40 \mathrm{~nm}$ ) to $35 \mathrm{GPa}$. The nanoanatase was observed to a pressure above $20 \mathrm{GPa}$. Direct transformation to the baddeleyite $\mathrm{TiO}_{2}$ polymorph was seen at $18 \mathrm{GPa}$. High temperature in situ micro X-ray diffraction studies have been performed by Seelaboyina et al. [7] on nanocrystalline and bulk samples of $\mathrm{NiO}$, anatase $\mathrm{TiO}_{2}$, and $\mathrm{ZnO}$. The lattice parameters of bulk and nanosamples were determined from $475-141 \mathrm{~K}$ for $\mathrm{NiO}, 300-883 \mathrm{~K}$ for $\mathrm{TiO}_{2}$, and $300-1426 \mathrm{~K}$ for $\mathrm{ZnO}$. The results obtained in this study show that the volume thermal expansion coefficient of nanocrystalline $\mathrm{NiO}$ is higher than that of bulk $\mathrm{NiO}$. The volume thermal expansion coefficient $\left(\alpha_{T}\right)$ of $\mathrm{n}-\mathrm{TiO}_{2}$ was measured approximately the same as that of the bulk $\mathrm{TiO}_{2}$. An increase in the volume thermal expansion coefficient $\left(\alpha_{T}\right)$ of $\mathrm{n}-\mathrm{ZnO}$ over bulk $\mathrm{ZnO}$ is observed. The high-pressure behavior of Ni-filled and Fefilled multiwalled carbon nanotubes has been investigated up to $27 \mathrm{Gpa}$ and $19 \mathrm{GPa}$ with the help of synchrotronbased angle-dispersive X-ray diffraction [8]. The structural transformation in CdSe nanocrystals has been studied [9] using high-pressure $\mathrm{X}$-ray diffraction and pressure optical absorption at room temperature. The nanocrystal undergoes a wurtzite to rocksalt transition analogous to that observed in bulk CdSe. The compression behavior of $\mathrm{Rb}_{3} \mathrm{C}_{60}$ was first measured by $\mathrm{X}$-ray diffraction under hydrostatic pressure up to $2.8 \mathrm{GPa}$ in a diamond anvil cell (DAC) at $300 \mathrm{~K}$ by Wang et al. [10]. The compressibility of $\mathrm{Rb}_{3} \mathrm{C}_{60}$ was later remeasured by Ludwig et al. [11] up to $6 \mathrm{GPa}$ using similar technique. An examination of previous Equation of State studies on $\mathrm{Rb}_{3} \mathrm{C}_{60}$ using a DAC revealed that the technique has limited accuracy in the pressure range up to $1.5 \mathrm{GPa}[12] \cdot \gamma-\mathrm{Fe}_{2} \mathrm{O}_{3}$ nanocrystal reveals different behaviour under high pressure. The $\gamma-\mathrm{Fe}_{2} \mathrm{O}_{3}$ nanocrystal was synthesized using microemulsion method in the system of water toluene, coated with dodecyl benzene sulphonic by Piermarini et al. [13]. The sample was characterized by using high-resolution transmission electron microscopy (HRTEM), which displays that the nanocrystals are spherical. It has been found that there is a phase transition of $\gamma-\mathrm{Fe}_{2} \mathrm{O}_{3}$ to $\alpha-\mathrm{Fe}_{2} \mathrm{O}_{3}$ when pressure reached $25 \mathrm{GPa}$ [14].

Due to the possibilities of substantially different behavior compared to the bulk, studies of nanocrystalline materials under high pressure and high temperatures are of considerable current interest. Application of high pressure may induce several effects on nanomaterial, and Equation of State is one of the useful tools to study these effects, that is, effect on thermoelastic properties such as Volume compression, bulk modulus, and thermal expansion. Due to such effects, several researchers have attracted the attention to the effect of pressure on nanomaterials. For this pressure versus volume relation of condensed matter known as Equation of State is a vital input. No doubt many Equation of State exist in the literature, but still there is a need to judge their suitably under strong compression. In the present study we are analyzing an empirically modified Equation of State for studying elastic properties of

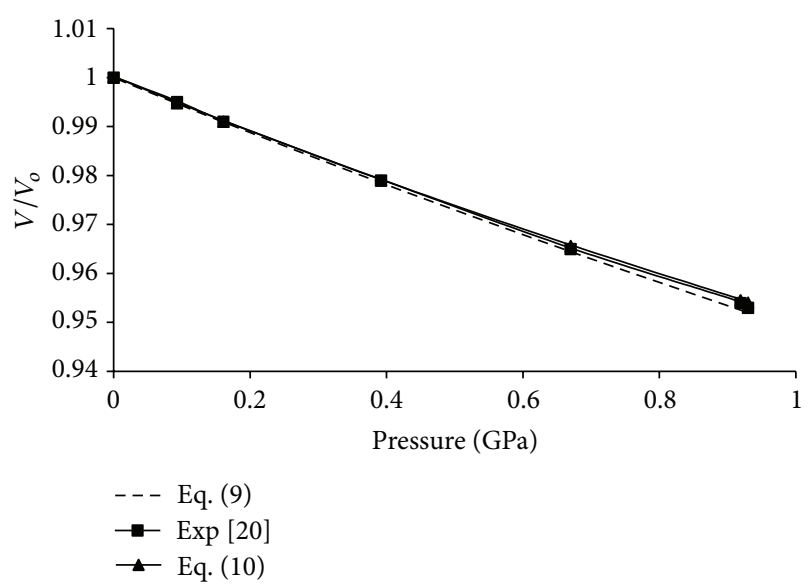

Figure 1: Pressure dependence of $V / V_{o}$ for $n-\mathrm{Rb}_{3} \mathrm{C}_{60}$.

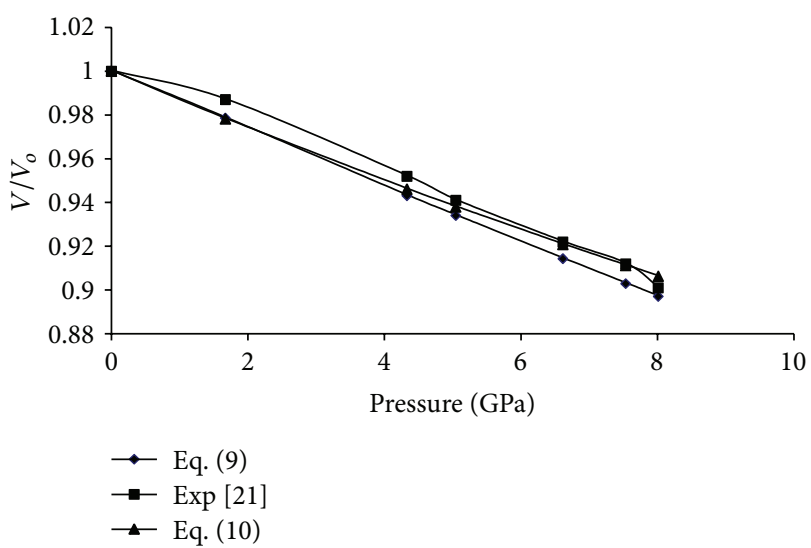

Figure 2: Pressure dependence of $V / V_{o}$ for $n$-CdSe.

nanomaterials under strong compression. Method of analysis is given in Section 1 followed by the results and discussion in Section 2.

\section{Method of Analysis}

The equation of state for a solid may be written as follows [15]:

$$
P=-\frac{d U}{d V}+P_{\mathrm{Th}},
$$

where $U$ is the lattice potential energy which is the function of volume only, by expanding $U$ in powers of $\Delta=V-V_{o}$.

With the help of Taylor series expansion, Shankar et al. [16] used the following truncated expression for the lattice potential energy:

$$
U=U_{o}+U_{o}^{\prime} \Delta+\frac{1}{2} U_{o}^{\prime \prime} \Delta^{2}+\frac{1}{6} U_{o}^{\prime \prime \prime} \Delta^{3},
$$

where $\Delta=V-V_{o}$,

$$
\frac{d U}{d V}=U_{o}^{\prime}+U_{o}^{\prime \prime} \Delta+\frac{1}{2} U_{o}^{\prime \prime \prime} \Delta^{2}
$$




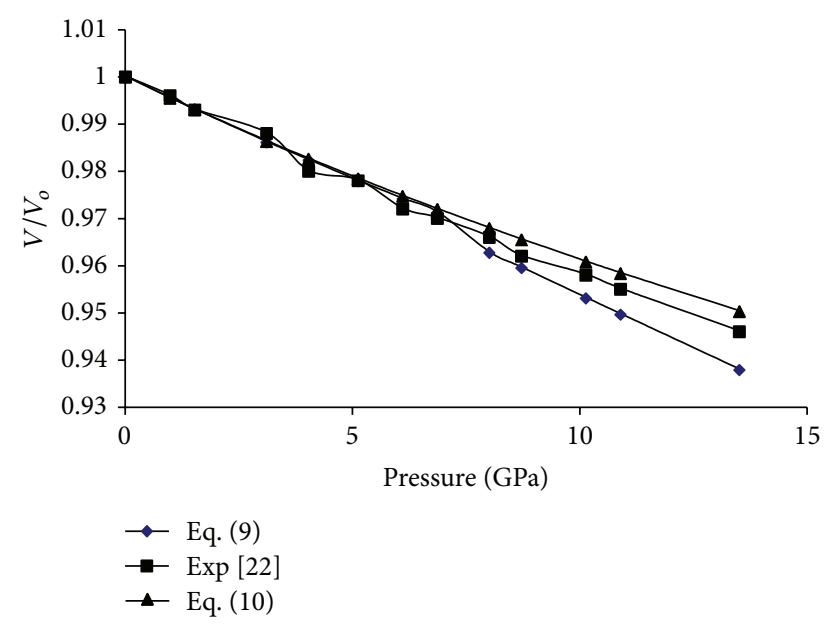

Figure 3: Pressure dependence of $V / V_{o}$ for $n-\mathrm{TiO}_{2}$ (rutile).

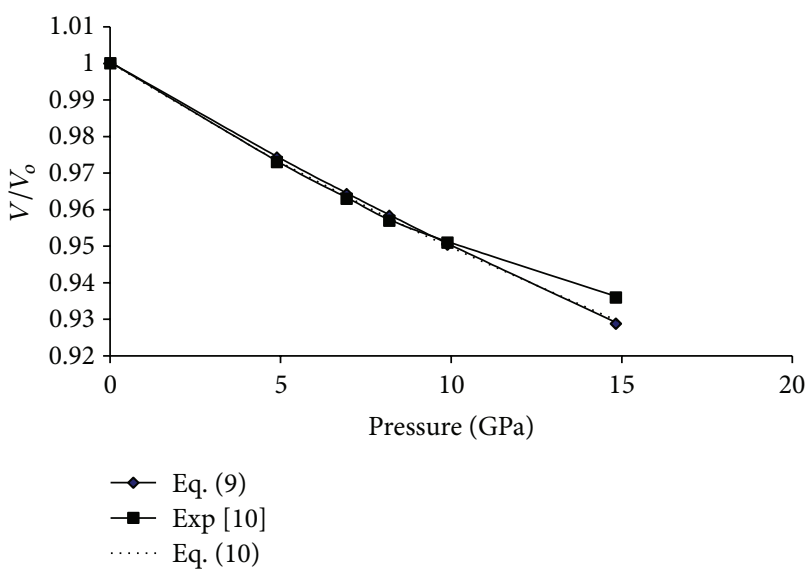

Figure 4: Pressure dependence of $V / V_{o}$ for $\mathrm{n}$-Fe filled nanotube.

where $U_{o}^{\prime}, U_{o}^{\prime \prime}$, and $U_{o}^{\prime \prime \prime}$ are the first-, second-, and thirdorder volume derivatives of $U$ taken at $V=V_{o}$. In view of equilibrium condition we have $U_{o}^{\prime}=0$. Values of $U_{o}^{\prime \prime}$ and $U_{o}^{\prime \prime \prime}$ are determined using the expressions for isothermal bulk modulus $K_{T}$ and its pressure derivative at $P=0$. The relations thus obtained are [16]

$$
\begin{gathered}
U_{o}^{\prime \prime}=\frac{K_{o}}{V_{o}}, \\
U_{o}^{\prime \prime \prime}=-\frac{K_{o}\left(K_{o}^{\prime}+1\right)}{V_{o}^{2}},
\end{gathered}
$$

where $K_{o}$ and $K_{o}^{\prime}$ are the values of $K_{T}$ and $d K_{T} / d P$ at $P=$ 0 . Using these equations Shanker et al. [16] obtained the following relation (at $P=0$ ):

$$
\frac{V}{V_{0}}-1=\frac{1-\left[1-2\left(\left(K_{0}^{\prime}+1\right) / K_{0}\right) P_{\mathrm{Th}}\right]^{1 / 2}}{K_{0}^{\prime}+1} .
$$

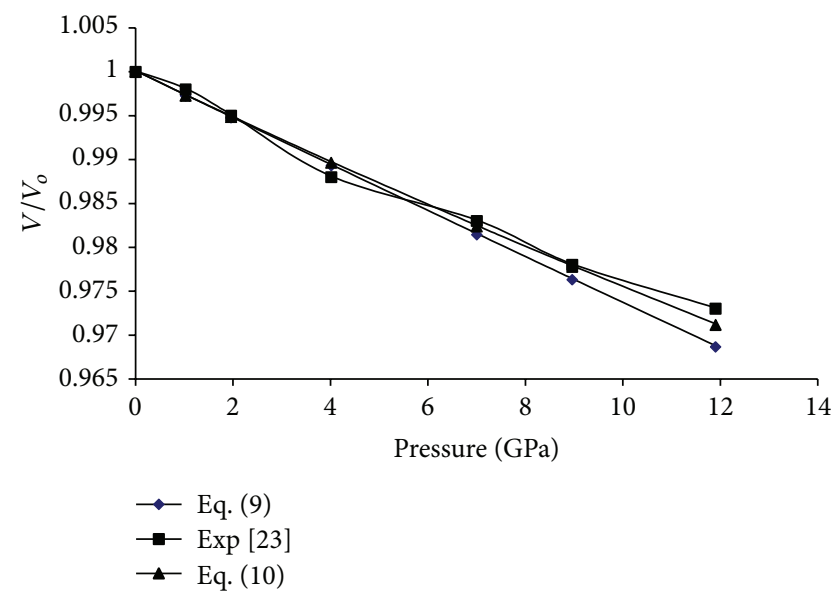

Figure 5: Pressure dependence of $V / V_{o}$ for nanocrystalline $\gamma$ - $\mathrm{Fe}_{2} \mathrm{O}_{3}$.

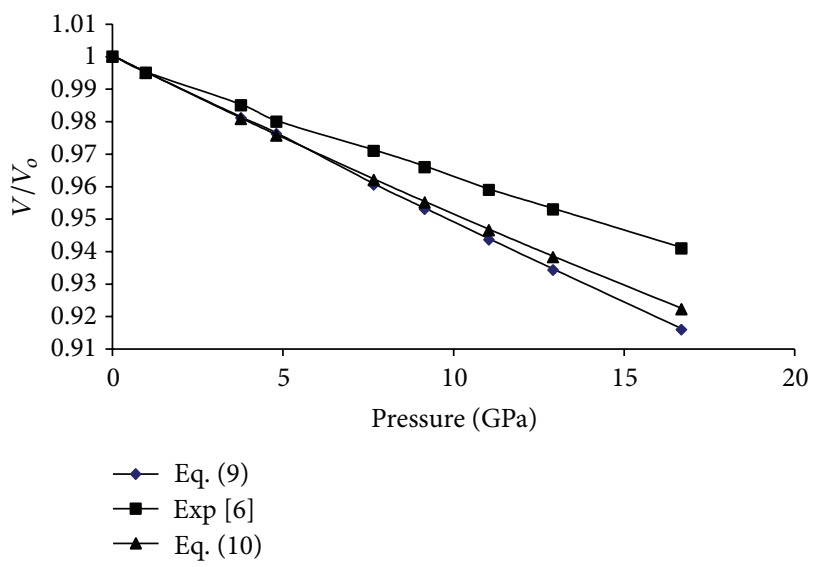

Figure 6: Pressure dependence of $V / V_{o}$ for $\mathrm{n}-\mathrm{TiO}_{2}$ (anatase).

Values of $V_{o}, K_{o}$, and $K_{o}^{\prime}$ all refer to the initial temperature $T_{o}$ and $P=0$. Under the effect of pressure, that is, when $P$ is not equal to zero, the above equation will yield to $[16,17]$

$$
\frac{V}{V_{0}}-1=\frac{1-\left[1-2\left(\left(K_{0}^{\prime}+1\right) / K_{0}\right)\left(P_{\mathrm{Th}}-P\right)\right]^{1 / 2}}{K_{0}^{\prime}+1} .
$$

When thermal pressure is zero $\left(P_{\mathrm{Th}}=0\right)$, (7) becomes

$$
\frac{V}{V_{0}}-1=\frac{1-\left[1+2\left(\left(K_{0}^{\prime}+1\right) / K_{0}\right) P\right]^{1 / 2}}{K_{0}^{\prime}+1} .
$$

Equation (8) may be rewritten as follows:

$$
P=K_{o}\left[\left\{1-\left(\frac{V}{V_{o}}\right)\right\}+\left\{\frac{\left(K_{0}^{\prime}+1\right)}{2}\right\}\left\{1-\left(\frac{V}{V_{o}}\right)^{2}\right\}\right] .
$$

Equation (9) has been found in a good agreement for low compression range for bulk materials [18], where almost all 
TABLE 1: Values of input parameters used in the present work.

\begin{tabular}{lcccc}
\hline Sl. no. & Nanomaterials & $K_{o}(\mathrm{GPa})$ & $K_{o}^{\prime}$ & References \\
\hline 1 & $\mathrm{n}-\mathrm{Rb}_{3} \mathrm{C}_{60}$ & 17.35 & 3.9 & {$[20]$} \\
2 & $\mathrm{n}$-CdSe (rocksalt phase) & 74 & 4.4 & {$[21]$} \\
3 & $\mathrm{n}-\mathrm{TiO}_{2}$-rutile & 211 & 8 & {$[22]$} \\
4 & $\mathrm{n}$-Fe filled $\mathrm{MWCNT}$ & 167 & 4 & {$[10]$} \\
5 & $\gamma-\mathrm{Fe}_{2} \mathrm{O}_{3}$ & 374 & 4 & {$[23]$} \\
6 & $\mathrm{n}-\mathrm{TiO}_{2}$-anatase & 190.4 & 4 & {$[6]$} \\
\hline
\end{tabular}

Equation of State give the same results, and Murnaghan Equation of State has been found to be the best. For higher compression range (9) fails. Therefore (9) is modified on an empirical basis. The modified formulation reads as follows and is already used to determine the volume compression for carbon nanotube bundles (bundle and individual tube) [19]:

$$
P=K_{o} \frac{V_{o}}{V}\left[\left\{1-\left(\frac{V}{V_{o}}\right)\right\}+\left\{\frac{\left(K_{0}^{\prime}+1\right)}{2}\right\}\left\{1-\left(\frac{V}{V_{o}}\right)^{2}\right\}\right] .
$$

\section{Results and Discussion}

In the present study the Equation of State model is used to study the volume compression in nanomaterials. Equation (9) is used to calculate the volume compression of six nanomaterials $\left(\mathrm{n}-\mathrm{Rb}_{3} \mathrm{C}_{60}, \mathrm{n}-\mathrm{CdSe}\right.$ (rocksalt phase), n- $\mathrm{TiO}_{2}$ (anatase and rutile phase), Fe-filled nanotube, and $\gamma-\mathrm{Fe}_{2} \mathrm{O}_{3}$ ). It is clear from the calculation that the Shanker Equation of State (9) gives good results at low compression, but for higher compression it deviates from the experimental points. Therefore to be appropriate for the higher compression (9) is modified empirically. Equation (10) is the modified Equation of State and is used to study the compression of abovementioned nanomaterials. Calculated values of relative volume change from (9) and (10) with pressure are shown in Figures 1, 2, 3, 4, 5, and 6 along with the experimental data. The input parameters required for the present study are given in Table 1. It is found that empirically modified Equation of State (10) improves the results of Shanker Equation of State (9) when compared with the available experimental results. This proves the validity of empirical high-pressure Equation of State for nanomaterials. It is pertinent to mention here that (9) and (10) have been derived in such a way that they are structure independent [18]; therefore they can also be used for bulk materials by taking input parameters corresponding to the bulk phase.

\section{References}

[1] J. Schiotz, F. D. Ditolla, and K. W. Jacobsen, "Softening of nanocrystalline metals at very small grain sizes," Nature, vol. 391, pp. 561-563, 1998.

[2] T. van Buuren, L. N. Dinh, L. L. Chase, W. J. Siekhaus, and L. J. Terminello, "Changes in the electronic properties of Si nanocrystals as a function of particle size," Physical Review Letters, vol. 80, no. 17, pp. 3803-3806, 1998.
[3] A. N. Goldstein, C. M. Echer, and A. P. Alivisatos, "Melting in semiconductor nanocrystals," Science, vol. 256, no. 5062, pp. 1425-1427, 1992.

[4] P. H. Borse, L. S. Kankate, F. Dassenoy, W. Vogel, J. Urban, and S. K. Kulkarni, "Synthesis and investigations of rutile phase nanoparticles of $\mathrm{TiO}_{2}$," Journal of Materials Science, vol. 13, no. 9, pp. 553-559, 2002.

[5] A. S. Povaremykh, Crystal Classification of Minerals, Plenum Press, New York, NY, USA, 1972.

[6] V. Swamy, L. S. Dubrovinsky, N. A. Dubrovinskaia et al., "Compression behavior of nanocrystalline anatase $\mathrm{TiO}_{2}$," Solid State Communications, vol. 125, no. 2, pp. 111-115, 2003.

[7] R. Seelaboyina, N. Phatak, R. P. Gulve, H. P. Leirmann, and S. K. Saxena, "Thermal expansion of nanocrystalline titanium dioxide $\left(\mathrm{TiO}_{2}\right)$, zinc oxide $(\mathrm{ZnO})$, nickel oxide $(\mathrm{NiO})$," Thermal Conductivity, vol. 27, pp. 647-666, 2005.

[8] H. K. Poswal, S. Karmakar, P. K. Tyagi et al., "High-pressure behavior of Ni-filled and Fe-filled multiwalled carbon nanotubes," Physica Status Solidi (B), vol. 244, no. 10, pp. 3612-3619, 2007.

[9] S. H. Tolbert and A. P. Alivisators, "The wurtzite to rock salt structural transformation in CdSe nanocrystals under high pressure," Journal of Chemical Physics, vol. 102, no. 11, article 4642, 15 pages, 1995.

[10] Z. Wang, S. K. Saxena, V. Pischedda, H. P. Liermann, and C. S. Zha, "In situ X-ray diffraction study of the pressure-induced phase transformation in nanocrystalline $\mathrm{CeO}_{2}$," Physical Review $B$, vol. 64, no. 1, Article ID 012102, 4 pages, 2001.

[11] H. A. Ludwig, W. H. Fietz, F. W. Hornung, K. Grube, B. Renker, and G. J. Burkhart, "The compressibility of $\mathrm{Rb}_{3} \mathrm{C}_{60}$ derived by $\mathrm{X}$-ray experiments under high pressure," Physica $C$, vol. 234, no. 1-2, pp. 45-48, 1994.

[12] J. S. Schilling and S. Klotz, "The influence of high pressure on the superconducting and normal state properties of high temperature superconductors," in Physical Properties of High Temperature Superconductors III, D. M. Ginsberg, Ed., p. 59, World Scientific, Singapore, 1992.

[13] G. J. Piermarini, S. Block, and J. D. Barnett, "Hydrostatic limits in liquids and solids to $100 \mathrm{kbar}$," Journal of Applied Physics, vol. 44, no. 12, pp. 5377-5382, 1973.

[14] J. Zhao, L. Guo, J. Liu, Y. Yang, R. Z. Che, and L. Zhou, "High bulk modulus of nanocrystal $\gamma-\mathrm{Fe}_{2} \mathrm{O}_{3}$ with chemical dodecyl benzene sulfonic decoration under high pressure," Chinese Physics Letters, vol. 17, no. 2, article 126, 2000.

[15] M. Born and K. Huang, Dynamical Theory of Crystal Lattice, Oxford University Press, New York, NY, USA, 1954.

[16] J. Shanker, S. S. Kushwah, and P. Kumar, "Theory of thermal expansivity and bulk modulus for $\mathrm{MgO}$ and other minerals at high temperatures," Physica B, vol. 233, no. 1, pp. 78-83, 1997.

[17] S. S. Kushwah, H. C. Shrivastava, and K. S. Singh, "Study of pressure-volume relationships and higher derivatives of bulk modulus based on generalized equations of state," Physica B, vol. 388, no. 1-2, pp. 20-25, 2007.

[18] M. Kumar, "Analysis of Suzuki, Shanker, and Kumar formulations under strong compressions," Journal of Physics and Chemistry of Solids, vol. 65, no. 6, pp. 1177-1180, 2004.

[19] M. Kumar and M. Kumar, "Empirical high pressure equation of state for nano materials," Indian Journal of Pure and Applied Physics, vol. 46, no. 6, pp. 378-381, 2008.

[20] O. Zhou, G. B. M. Vaughan, Q. Zhu et al., "Compressibility of $\mathrm{M}_{3} \mathrm{C}_{60}$ fullerene superconductors: relation between $T_{c}$ and lattice parameter," Science, vol. 255, no. 5046, pp. 833-835, 1992. 
[21] S. H. Tolbert and A. P. Alivisators, "The wurtzite to rock salt structural transformation in CdSe nanocrystals under high pressure," Journal of Chemical Physics, vol. 102, no. 11, article 4642, 15 pages, 1995.

[22] J. S. Olsen, L. Gerward, and J. Z. Jiang, "High-pressure behavior of nano titanium dioxide," High Pressure Research, vol. 22, no. 2, pp. 385-389, 2002.

[23] J. Zhao, L. Guo, J. Liu, Y. Yang, R. Z. Che, and L. Zhou, "High bulk modulus of nanocrystal $\gamma-\mathrm{Fe}_{2} \mathrm{O}_{3}$ with chemical dodecyl benzene sulfonic decoration under high pressure," Chinese Physics Letters, vol. 17, no. 2, article 126, 2000. 

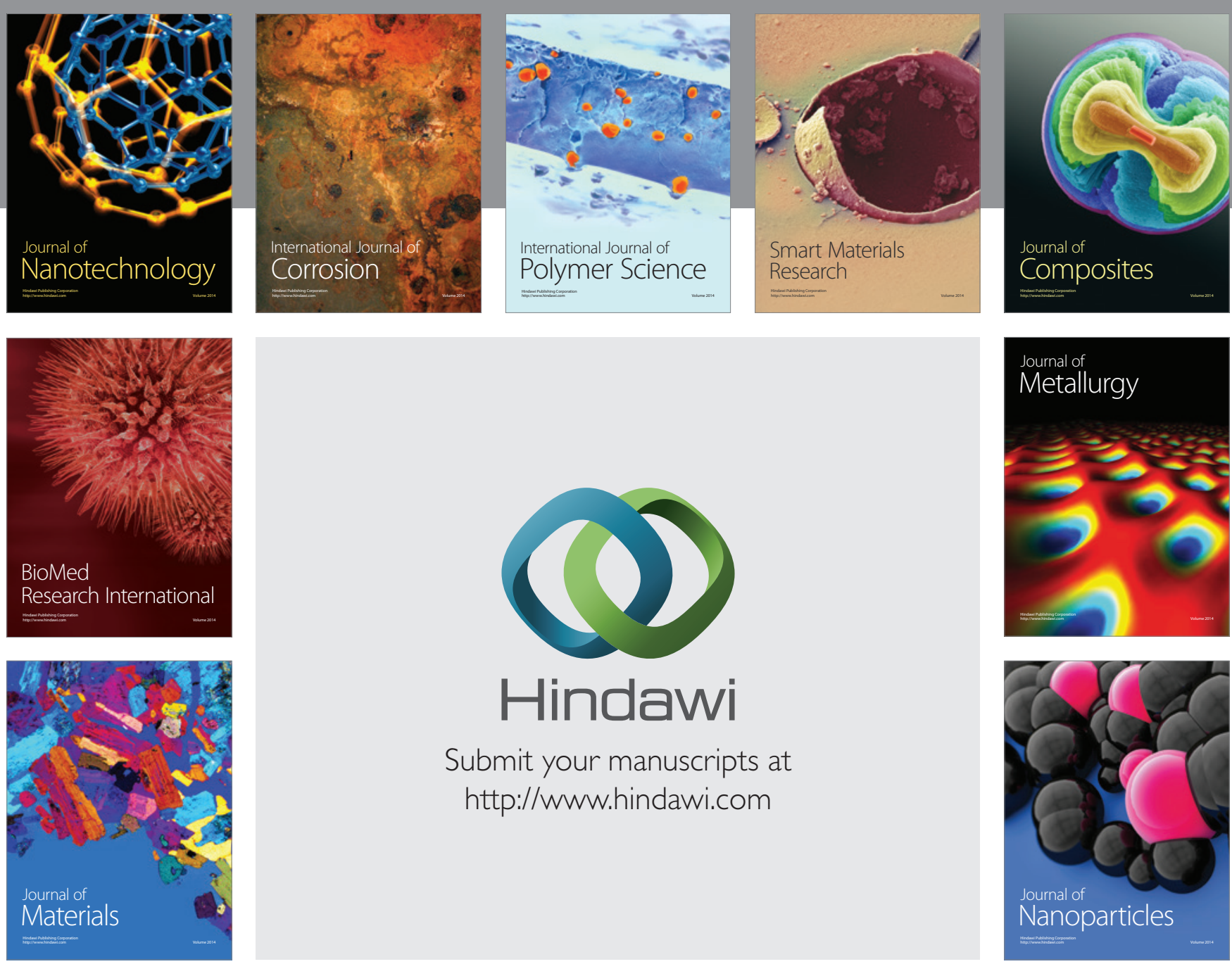

Submit your manuscripts at http://www.hindawi.com
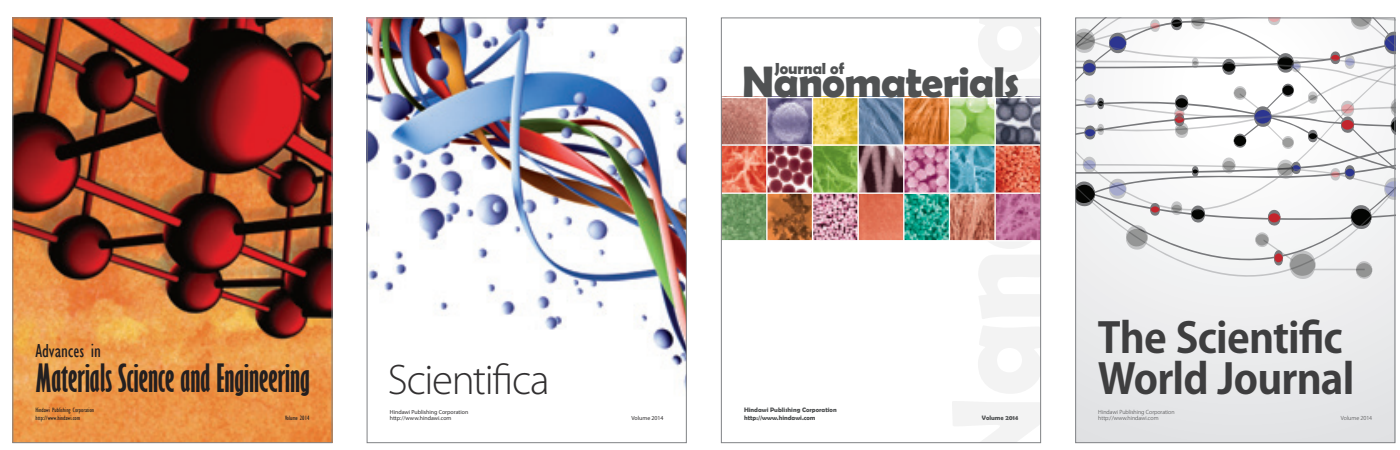

\section{The Scientific World Journal}
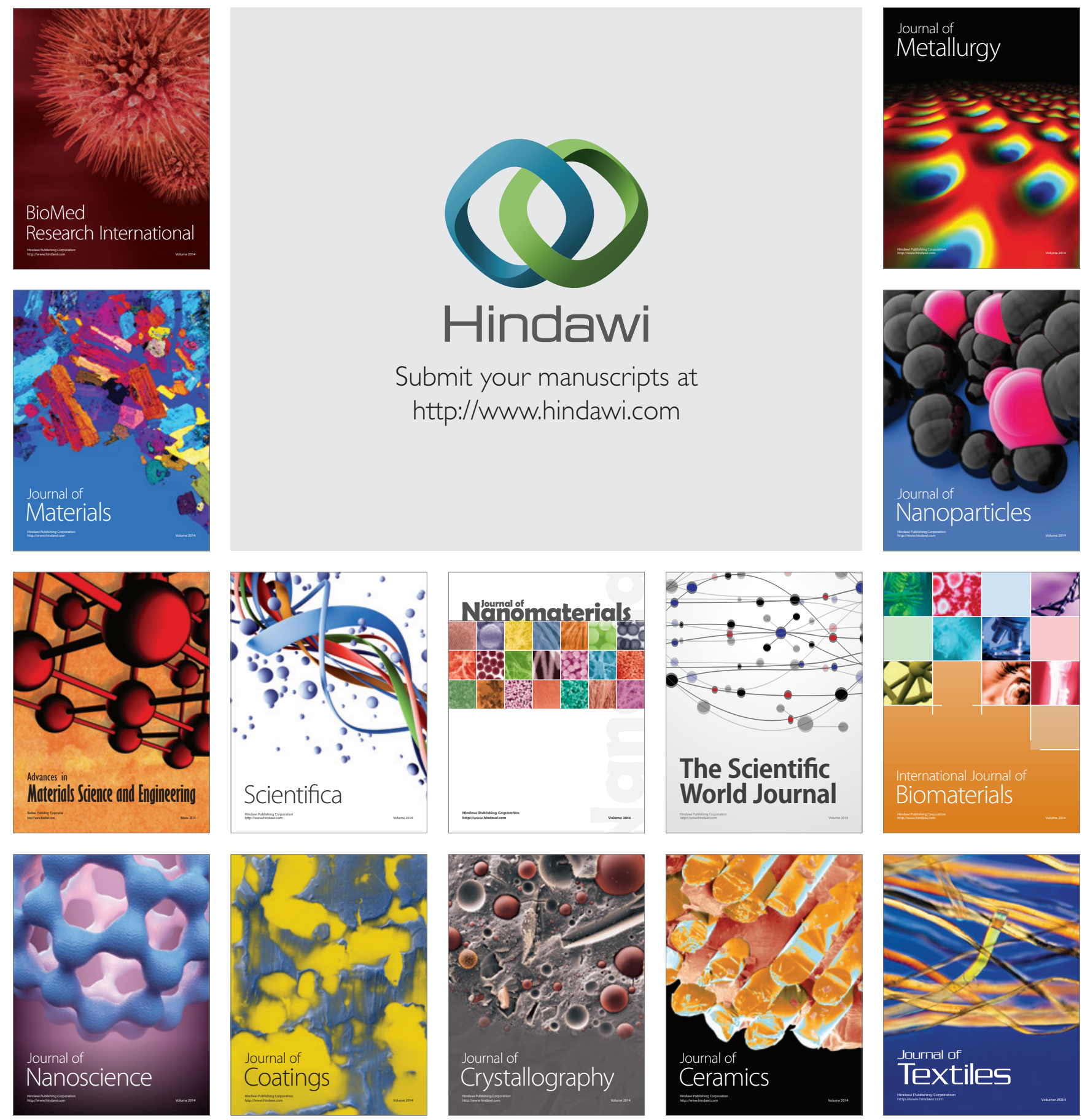